\title{
Radar Cross Section Analysis of Unmanned Combat Aerial Vehicle (UCAV) using FEKO Software
}

\author{
J P Sijabat ${ }^{1, *}$, T Indriyanto ${ }^{1}$ \\ 1 Faculty of Mechanical and Aerospace Engineering, Institute of Technology Bandung, Jl. Ganesha 10 \\ Bandung 40132, Indonesia \\ * Correspondence: jeps96@gmail.com
}

Received: 12 July 2020; Accepted: 30 October 2020; Published: 20 December 2020

\begin{abstract}
Radar technology development encourages each country to develop military aircraft with small Radar Cross Section (RCS) size to bring out stealth behaviour, so that it is not easily detected by the enemy. In designing an airplane, computational methods become one of the best solutions in simulating the behaviour of an aircraft geometry when illuminated by electromagnetic waves. On this study, a calculation simulation of the RCS value was performed using FEKO (FElding bei Körn mit beliebiger Oberfläche) EM Simulation software for unmanned combat aerial vehicles (UCAV). Simulations are carried out in various conditions to find out factors affecting RCS value. These factors were analysed by varying radar frequency, material coating the plane, and methods of computational calculation. The results show that the greater the frequency, the greater the computational resources required as on higher number of mesh, more time needed to run the simulation, and required memory. However, the frequency is not directly proportional to the RCS value of the object. Methods of Momentum (MoM) and Multilevel Fast Multipole Method (MLFMM) perform computation calculations that are more detailed and more accurate compared to Physical Optic (PO) full-ray tracing.
\end{abstract}

Keywords: FEKO simulation, radar cross section, stealth

\section{Introduction}

Radar is a technology that must be possessed by objects that have the need to detect other objects in their surroundings. The history of radar began when a British physicist named James Clerk Maxwell developed the basics of the theory of electromagnetics in 1865. A year later, a German physicist named Heinrich Rudolf Hertz managed to prove Maxwell's theory of electromagnetic waves by discovering electromagnetic waves themselves [1].

Radar concept itself was first introduced by Christian Hülsmeyer in 1904. The real form of detection was carried out by showing the ability of electromagnetic waves to detect the presence of a ship in thick foggy weather. Radar technology developed rapidly triggered by the presence of war zones throughout the 1950s and 1960s. Radar typically used the VHF frequency range (30 to 300 $\mathrm{MHz}$ ) as well as UHF ( $300 \mathrm{MHz}$ to $3 \mathrm{GHz}$ ). The growing of radar technology makes it important to have war devices that cannot be detected by radar or have a small RCS [2].

Until now, the lowest RCS value is claimed for F-22 aircraft with value of $0.0001 \mathrm{~m}^{2}$. This value is achieved by using geometry and Radar Absorbing Materials (RAM) that are very optimal. The nature of the discussion or knowledge of the measurement of RCS values is very fundamental to be disseminated and related to the defense of a country. 
This research was performed to explore the effect of radar frequency, coating materials and the use of computational methods to the RCS values of a UCAV, and compared the results with those from references and previous studies.

\section{Methodology}

In general, the RCS of a target is a function of the polarization of the incoming radar wave, angle of arrival, angle of observation, target geometry, electrical properties of the target and the operating radio frequency. Thus, two targets with the same physical size and similar shapes can have different RCS plots.

According to IEEE RCS, is is defined that, "A measure of reflective strength is defined as $4 \pi$ times the ratio of the power per unit of solid angle scattered in a specified direction to the power per unit are in a plane wave incident on the scatterer from a specified direction. More precisely, it is the limit of the ratio as the distance from the scatterer to the point where the scattered power is measured approaches infinity."

Mathematically the RCS value () of an object can be written as [3]:

$$
\sigma(\theta, \phi)=\lim _{R \rightarrow \infty} 4 \pi R^{2} \frac{\left|E_{\text {scat }}\right|^{\overline{2}}}{\left|E_{\text {inc }}\right|^{2}}
$$

where:

$\theta, \phi$ are the angles at which the object is seen from radar,

$\mid$ Einc $\left.\right|^{2}$ is the electric field due to polarized plane wave and propagation vector,

$\mid$ Escat $\left.\right|^{2}$ is the scattered far field, and

$R$ is the distance from radar transmitter to target.

The goal to reduce the RCS of military aircrafts such as fighters and UCAVs is directly related to the distance at which it can be detected by enemy radars [2,3]. The radar equation given below provides a quantitative way to analyse the impact of RCS reduction to its detection distance for monostatic radars [3]:

$$
\mathrm{R}_{\max }=\sqrt[4]{\frac{G^{2} \lambda^{2} P_{t} \sigma}{(4 \pi)^{3} P_{\min } L}}
$$

where:

$\mathrm{Rmax}$ is the maximum range of the radar detection,

$P t$ is the radar antenna's transmission power,

$P$ min is the minimum power detected by the radar,

$G$ is the radar gain, and

$L$ is the losses associated to the radar electronics and the environment.

From equation (2) it is obvious that among the variables of the radar equation, only one possible control by the target aircraft is its RCS, while other factors are inherent to either the hostile radar system or the environment.

In this study all RCS simulations were modelled and run on the same hardware with specification as follows:

1. Processor : Intel(R), Xeon(R), CPU E5-2697 v3 @2,60GHz 2,60GHz

2. System type :64-bit Operating System

3. Operating System : Windows 7 Home Edition

4. RAM : $128 \mathrm{~GB}$

The flowchart of this study is depicted by Figure 1. 


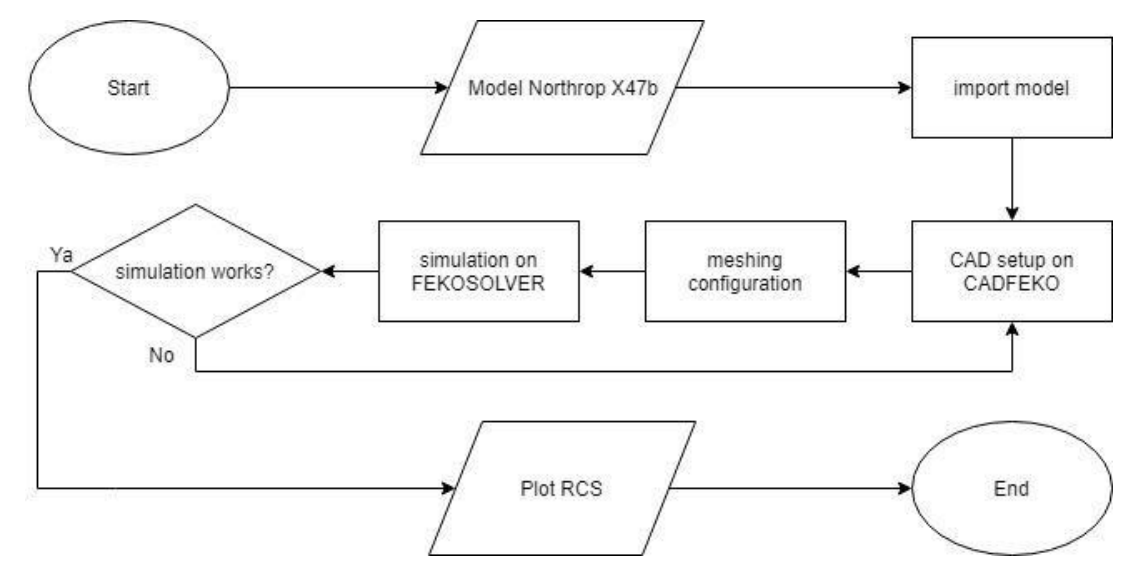

Figure 1. Flowchart of simulation

Firstly, the Northrop X-47B UCAV is modelled on CATIA using real dimension obtained from its official 3-view drawing. The model is then exported in "stp" extensions and imported to CADFEKO for further modification as necessary. Figure 2 shows in detail a 3D model of the object target.

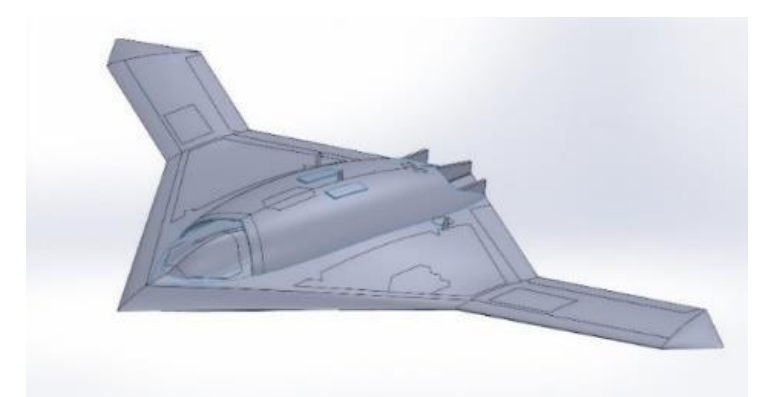

Figure 2. 3-D perspective model of the UCAV developed with CATIA software

The simulation was conducted using three scenarios and a general set up. The general set up was applied to all simulation scenarios as shown on Table 1 . The first simulation scenario is performed to investigate the effects of radar frequency variation to RCS which are performed on four different frequency runs. The second simulation scenario is run to study the effects of surface coating material to RCS in terms of its relative permittivity. The third simulation scenario is used to explore the effects of simulation method to RCS estimation, in which comparisons were made between full wave solver of MLFMM and PO which generally needs lesser computing resources.

\section{Results and Discussions}

Scenario 1 simulation result shows that higher frequency simulation requires higher total mesh elements and computing resource than lower frequency band as depicted on Figure 3 and shown on Table 1. However, higher frequency used did not always result in higher RCS values as shown on Table 4. Overall RCS varies between $-24-13 \mathrm{~dB}$ or $0.004-20 \mathrm{~m} 2$. Frontal aspects always give lower RCS values, in this case between $-24--16 \mathrm{~dB}$ or $0.004-0.025 \mathrm{~m} 2$; while rear aspects almost always result in highest values, i.e. between $-19.5-13 \mathrm{~dB}$ or $0.011-20 \mathrm{~m} 2$.

Scenario 2 simulation result shows that different coating material on the aircraft surface illuminated by planewave radar affect the RCS plot as shown on Figure 7. Surface coating material with higher value of relative permittivity $\odot r$ (Alumina with $\odot r=9.75$ ) requires more running time in the simulations as shown on Table 3. 


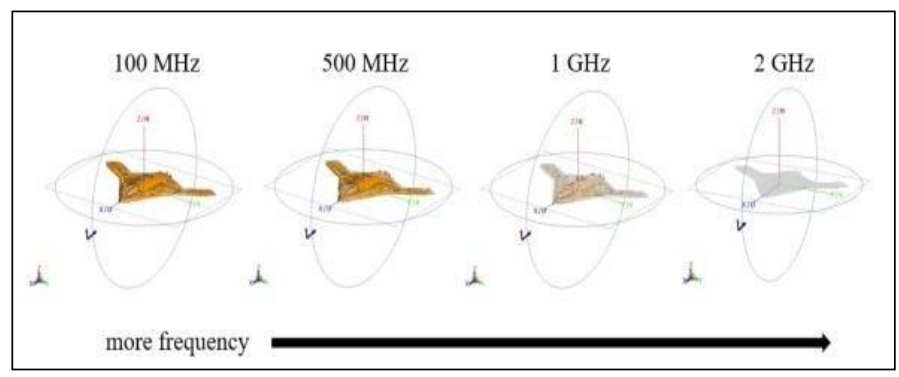

Figure 3. Mesh configuration display for scenario 1

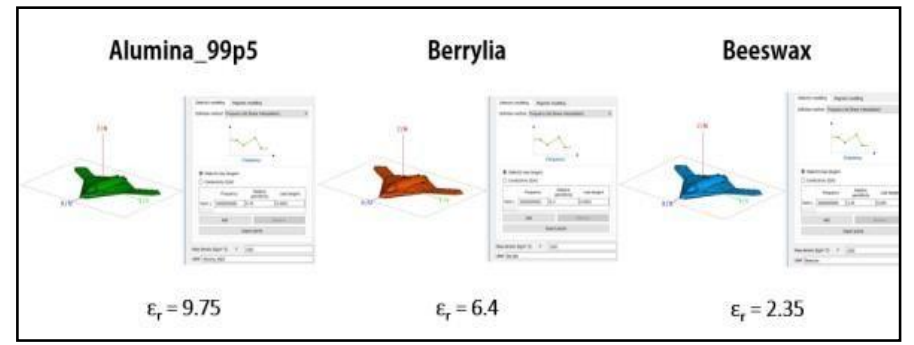

Figure 4. Mesh configuration display for scenario 2

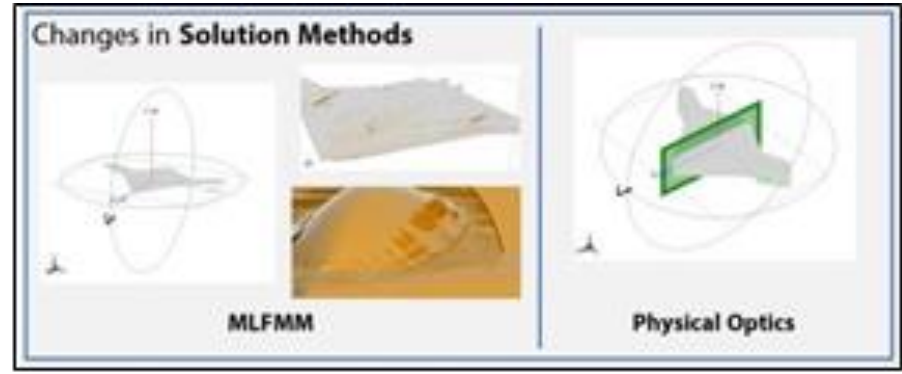

Figure 5. Mesh configuration display for scenario 3

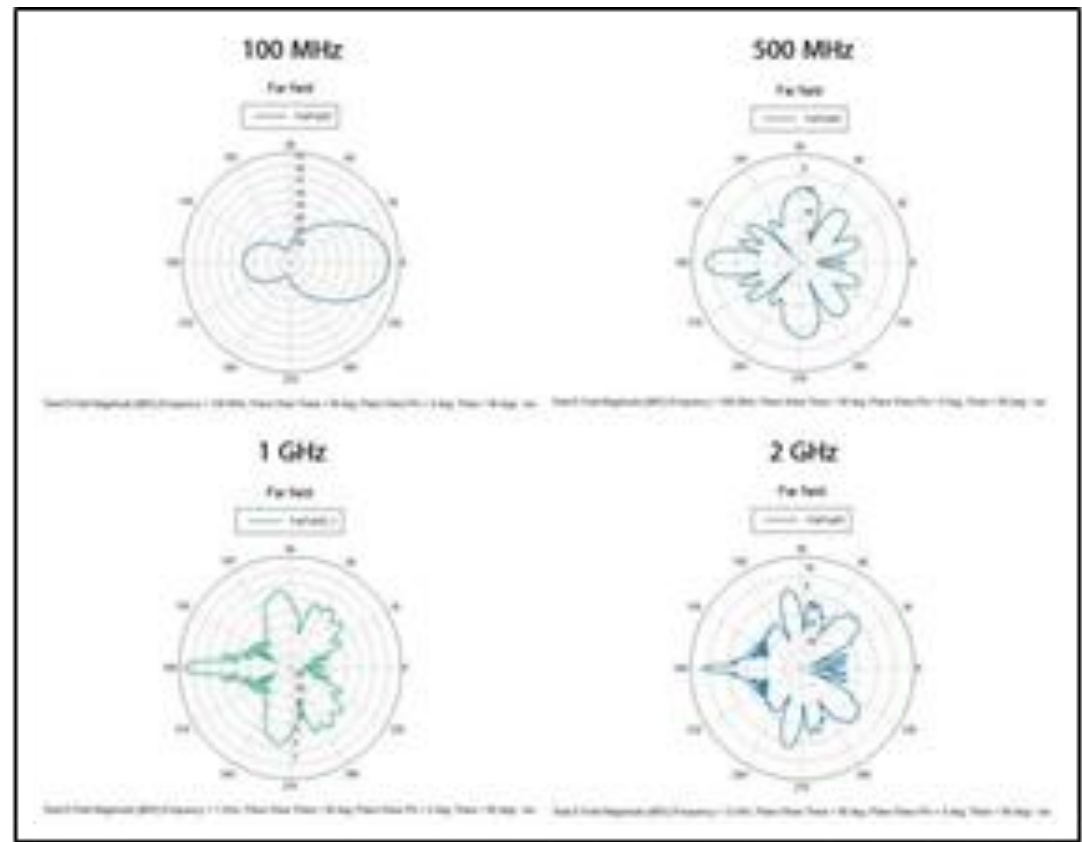

Figure 6. Scenario 1- RCS plot for various radar frequency 


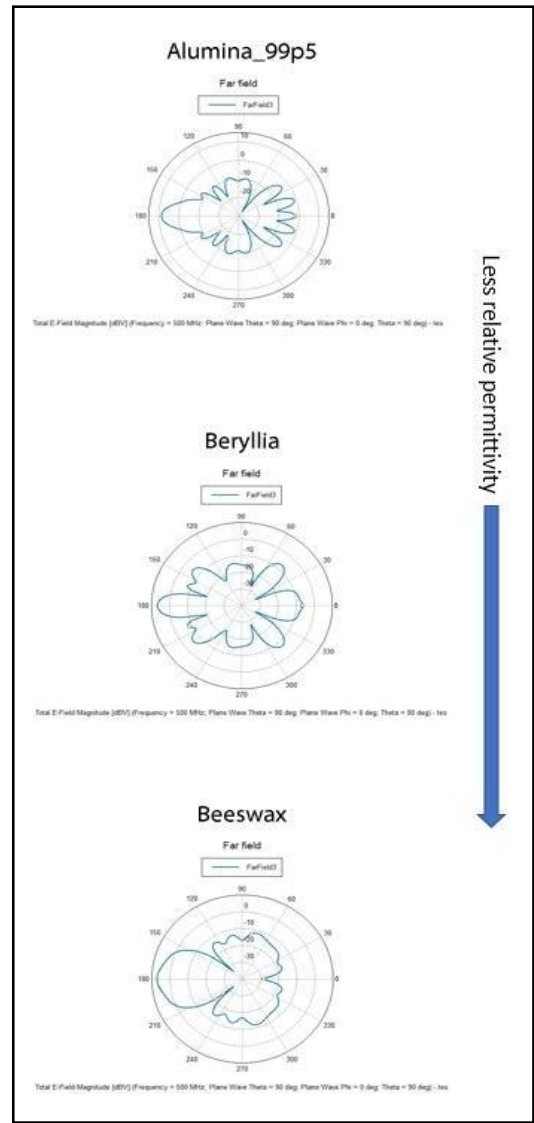

Figure 7. Scenario 2- RCS plot for various coating materials

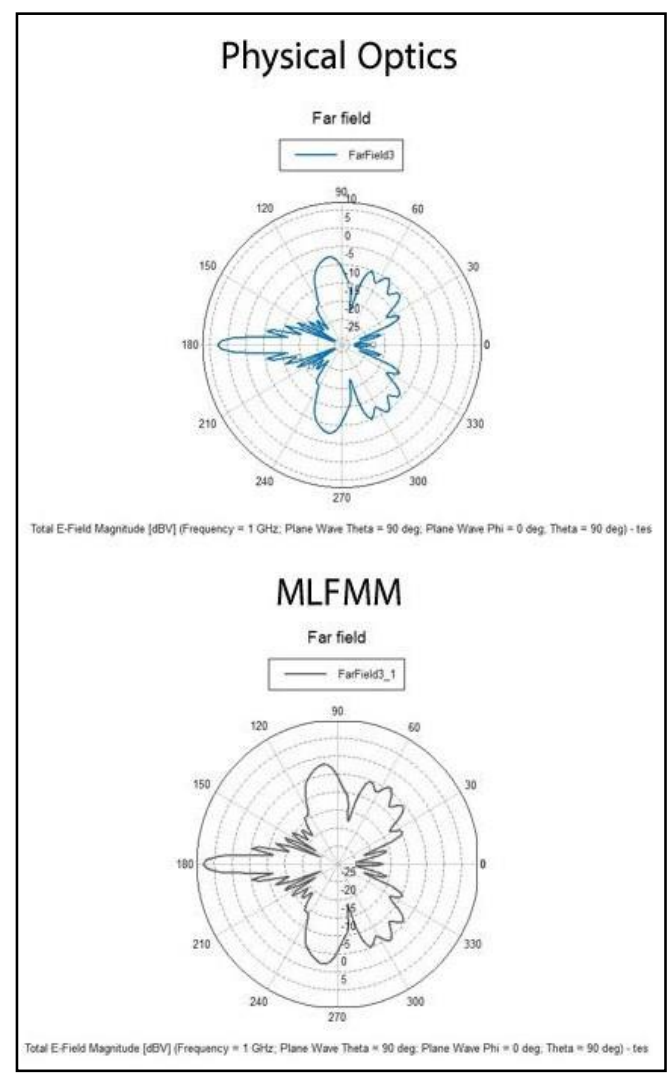

Figure 8. Scenario 3- RCS plot for various calculation methods

Table 1. Resources required for variation of radar frequency with the $1^{\text {st }}$ scenario

\begin{tabular}{ccccc}
\hline \multirow{2}{*}{ Frequency $(\mathrm{GHz})$} & \multirow{2}{*}{$\begin{array}{c}\text { Total mesh } \\
\text { elements }\end{array}$} & \multicolumn{2}{c}{ Memory $(\mathrm{MB})$} & \multirow{2}{*}{$\begin{array}{c}\text { Running time } \\
(\mathrm{s})\end{array}$} \\
\cline { 3 - 4 } & 7,814 & 24 & $0.360 \times 10^{3}$ & 137 \\
.5 & 35,594 & 68 & $1.025 \times 10^{3}$ & 1,538 \\
1 & 154,540 & 268 & $4.032 \times 10^{3}$ & 15,542 \\
2 & 886,231 & 1,428 & $2.1325 \times 10^{4}$ & 30,228 \\
$4^{*}$ & $2,904,557$ & - & - & - \\
\hline
\end{tabular}

*simulation on $4 \mathrm{GHz}$ cannot be executed due to hardware limitation

Table 2. Resources required for variation of surface coating material with the $2^{\text {nd }}$ scenario

\begin{tabular}{llllc}
\hline \multirow{2}{*}{$\begin{array}{l}\text { Surface } \\
\text { Material }\end{array}$} & $\begin{array}{l}\text { Total mesh } \\
\text { elements }\end{array}$ & Each process & Total & Running time \\
$(\mathrm{s})$
\end{tabular}


Table 3. Resources required for variation of computational method in scenario 3

\begin{tabular}{llccc}
\hline \multirow{2}{*}{ Methods } & $\begin{array}{l}\text { Total mesh } \\
\text { elements }\end{array}$ & \multicolumn{2}{c}{ Memory $(\mathrm{MB})$} & \multirow{2}{*}{$\begin{array}{c}\text { Running time } \\
(\mathrm{s})\end{array}$} \\
\cline { 3 - 4 } & 154,540 & Each process & Total & 1,270 \\
PO & $1,572,678$ & $196,998 \times 10^{3}$ & $2.693 \times 10^{6}$ & - \\
MoM $^{*}$ & $1,478,990$ & 1,176 & $10.765 \times 10^{3}$ & 13,540 \\
\hline
\end{tabular}

*simulation using MoM method cannot be performed due to hardware limitation

Table 4. RCS values on frontal, lateral and rear portions in scenario 1

\begin{tabular}{ccccc}
\hline \multirow{2}{*}{ Angle $\theta$} & \multicolumn{4}{c}{ RCS value $(\mathrm{dBs})$} \\
\cline { 3 - 4 } & $100 \mathrm{MHz}$ & $500 \mathrm{MHz}$ & $1 \mathrm{GHz}$ & $2 \mathrm{GHz}$ \\
\hline $0^{\circ}$ & $-16,5$ & -20 & $-17,5$ & -24 \\
$90^{\circ}$ & -20 & -14 & -10 & -4.5 \\
$180^{\circ}$ & $-19,5$ & 3 & 8 & 13 \\
\hline
\end{tabular}

Table 5. RCS values on frontal, lateral and rear portions in scenario 3

\begin{tabular}{cll}
\hline \multirow{2}{*}{ Angle $\theta$} & - & \multicolumn{2}{l}{ RCS value $(\mathrm{dBs})$} \\
\cline { 2 - 2 } & MLFMM & PO \\
\cline { 2 - 3 } $0^{\circ}$ & $-17,5$ & -21 \\
$90^{\circ}$ & -10 & -13 \\
$180^{\circ}$ & 8 & 3 \\
\hline
\end{tabular}

Scenario 3 simulation result shows the same RCS pattern for both full-wave equation solution using MLFMM and PO methods as depicted on Figure 8. Computationally, MFLMM requires more memory and running time due to its higher number of mesh element generated, while PO requires less with smaller number of mesh element as shown on Table 3. With similarity of the result for both methods, PO is a better and more precise scheme for objects with large electrical geometry [4-6].

\section{Conclusions}

From the results and analysis above it can be concluded that the RCS values of Northrop X- 47B UCAV in general were affected by radar frequency radiated by the planewave radar and surface materials. However, the increase of RCS values with frequency do not show a linear pattern (higher frequency did not always means higher RCS values). Theoretically, significant frequency increase will change the scattering region behaviour of an object illuminated by radar. Results from the second scenario showed that different surface materials will change the behaviour of object geometry illuminated by radar. Different coating materials could result in different RCS values. The use of radar absorbing material proved to reduce RCS values for stealth aircraft. From the third scenario it is concluded that full-wave numerical calculations, in this research is MLFMM, are limited to structures of several wavelengths in size. Application to larger geometry and higher frequency planewave is hardly possible because of the difficulty in meshing requirement, large memory consumption and lengthy computation times. The PO approach discussed in this paper is a good alternative method to be applied for electrically large structures such as aircraft and ships. The above results were in a good agreement with other previous studies. 


\section{Acknowledgments}

This research was supported by ITB and PT. Dirgantara Indonesia.

\section{References}

1. IEEE-Standard Association. (1996). "The IEEE Standard Dictionary of Electrical and Electronics Terms", 6th edition. IEEE.

2. Gama, A.M., Rezende, M.C. and Dantas, C.C. (2011). “Dependence of microwave absorption properties on ferrite volume fraction in MnZn ferrite/rubber radar absorbing materials", Journal of Magnetism and Magnetic Materials, Vol. 323, No. 2, pp. 2782-2785. doi: 10.1016/j.jmmm.2011.05.052.

3. Knott, E.F., Schaeffer, J.F. and Tuley, M.T. (1993). “Radar Cross Section”, 2nd edition, Artech House Inc., USA.

4. Syahtrian, Afif (2018). "Perhitungan Dan Analisis Radar Cross Section Untuk Pesawat Tempur F-22 dengan Perangkat Lunak FEKO”. Bachelor's Thesis. Indonesia: Institut Teknologi Bandung.

5. Hapsoro, Andry (2018). "Perhitungan dan Analisis Radar Cross Section Untuk Missile AIM- 9M Sidewinder dengan Perangkat Lunak FEKO”. Bachelor's Thesis. Indonesia: Institut Teknologi Bandung.

6. Yuana, Yuna (2018). “Analisis Radar Cross Section Pesawat Hypothetical Fighter dengan Menggunakan Perangkat Lunak FEKO”. Master's Thesis. Indonesia: Institut Teknologi Bandung.

This is an open-access article distributed under the terms of the Creative Commons Attribution 4.0 International License, which permits unrestricted use, distribution, and reproduction in any medium provided the original work is properly cited. 